\title{
Article \\ Computational fatigue durability of butt welds with cracks in the flanges of the solid-web girder of the railway bridge
}

\author{
Bernard Wichtowski ${ }^{1, *}$ \\ 1 West Pomeranian University of Technology, Szczecin, Poland \\ * Correspondence: Prof. Bernard Wichtowski, marek.wichtowski@zut.edu.pl
}

Received: 12.03.2019; Accepted: 09.04.2019

\begin{abstract}
In 2018, passed the 40th anniversary of the death of prof. Andrzej Fabiszewski (1924-1978), a forerunner of testing the quality of butt welds in exploited railway bridges. One of the first surveyed facilities was the viaduct on the Poznan-Szczecin line discussed in the article. A very bad state of welds was found and there were 61 internal cracks. In order to estimate the durability of the facility, strength tests of the steel of the structure were carried out and static calculations were made against standard and operational loads. The fatigue life of a crack in a flange joint of one girder was also analyzed. The results of these tests are included in the article.
\end{abstract}

Keywords: steel bridges; fusion-welded joints; fatigue strength

\section{Introduction}

Due to the progressive degradation of the bridge infrastructure, the issue of its sustainability is a global problem. Since the seventies of the twentieth century, it has been assumed that the quality of welds is of decisive importance for the durability of welded structures. The influence of welding incompatibilities, and in particular cracks in the welds, should be considered individually in accordance with the Fitness of Purpose methodology. According to the Fitness of Purpose method, it is possible to determine whether a given welding incompatibility is acceptable from the point of view of fracture mechanics and the actual load state of the joint $[1 \div 4]$.

Already in the 1950s, the precursor of the Fitness of Purpose idea in Poland was prof. Andrzej Fabiszewski (1924-1978). It was thanks to the Professor under the agreement with the Ministry of Transport MK133-06-02-04, in 1954-1990, X-ray examinations of welds of the leading bearing girders of approximately 200 exploited bridges across the country were carried out. On the occasion of the 40th anniversary of the death of the Professor, his collaborators wish to bring the Professor's scientific activity closer with this article and article [5]. It was Professor Fabiszewski who in 1957-1958 described the results of tests of butt joints in 10 railway bridges, in which 984 roentgenograms of welded joints were made [6,7].

Negative test results for riveting joints with cracks in several objects. Among others: the first welded in Poland (from 1937-1939) four bridges on the railway line Nasielsk-Torun (1959), a nine-span truss bridge $(7 \times 66.0 \mathrm{~m}+2 \times 16.0 \mathrm{~m})$ by the Vistula River under The Citadel in Warsaw (1962) and a viaduct on the line Poznań-Szczecin $212.26 \mathrm{~km}$ (1958). The decision to strengthen cracked joints was made on the basis of calculations from static standard loads, without experimental and theoretical fatigue analysis $[3,8]$. The Paris' formula considered the first one, in which the values from the fracture mechanics $\mathrm{d} l / \mathrm{d} N=C(\Delta K)^{m}$ were taken into account in 1957, and the coefficients $\mathrm{C}$ and $\mathrm{m}$ are experimental factors (H. Takashima) from 1973, while the laboratory tests of cracks in the welds with rhombic overlays, the author carried out in the nineties of the twentieth century, obtaining the results shown in figure 1 [9].

Using the regression line equation from these tests, the useful life of the viaduct was determined, which was presented in [10] - figure 2. This analysis took into account the technical condition of the structure after repeated field tests in 1984. Durability should be understood as the number of load cycles that the girder can transfer from the beginning of the crack with a given length (width), to the growth of the crack to the critical dimension at which its avalanche propagation will begin (brittle fracture).

In recent years, several countries (Canada, the United States, the United Kingdom, Switzerland and Denmark) have adopted a new probabilistic assessment of the bearing capacity of used bridges. It is a method of separated, calibrated safety factors with reduced requirements in relation to newly designed structures - according to the author, the "redundancy" method [11]. Based on the requirements of this 
method and the Fitness of Purpose method, the article analyzes the fatigue life of the most dangerous fracture of the viaduct. In addition, the calculations are supposed to justify the purposefulness of reinforcement of flange welds with cracks, which was made in 1959.

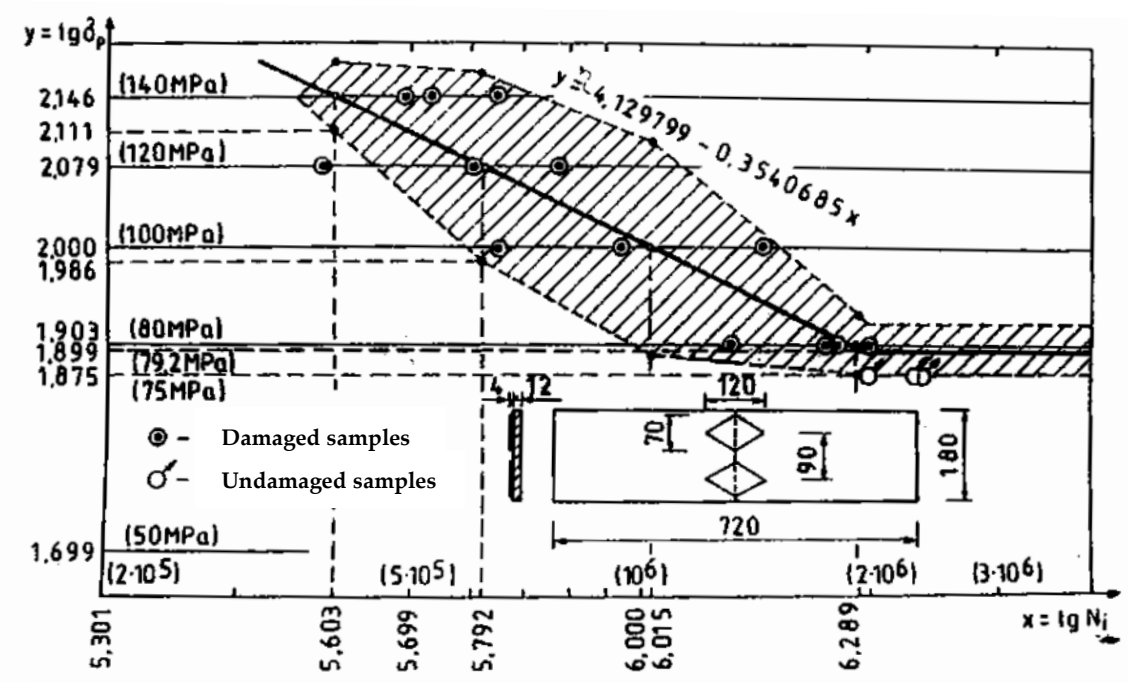

Fig.1. Regression line with the confidence interval and the results of fatigue tests of 16 samples ( $\sigma_{p}-$ range of pulsating stress, $N_{i}$ - number of load cycles)

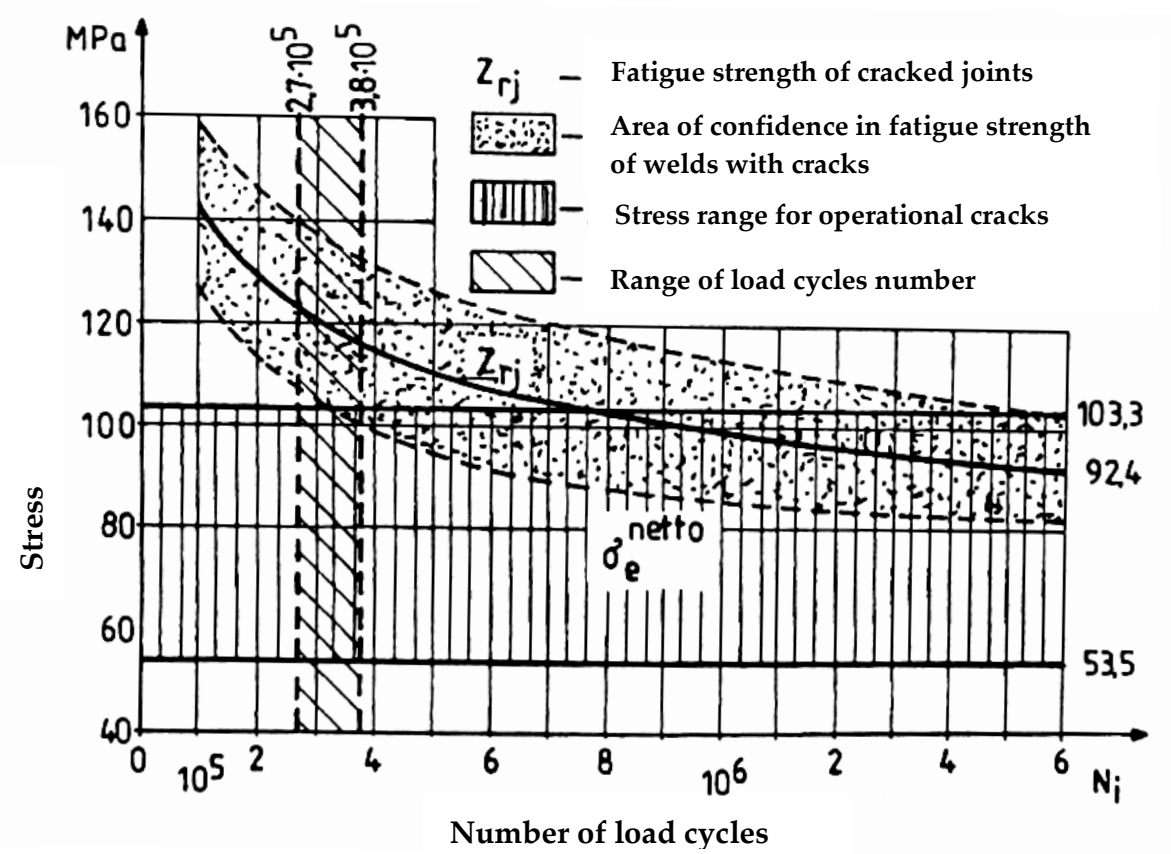

Fig. 2. Bridge service life in the function of $Z_{r j}, P_{o p r}$. and number of load cycles

\section{Viaduct construction and testing}

The supporting structure of the triple-track viaduct, with the bottom roadway, is 6 welded plate girders with a support span of $15.0 \mathrm{~m}$ (Fig. 3 and 4). The girders have a web with a section of $1700 \times 12 \mathrm{~mm}$, whose plates are joined at the length of the girder with two and exceptionally on the $\mathrm{F}$ bearer with three butt welds covered with double-sided gibs of $\mathrm{t}=8 \mathrm{~mm}$. These contacts are located at a distance of $4.50 \mathrm{~m}$ from supports on girders A, B (track No. 3) and C, D (track No. 2) and at distances $0.76 \mathrm{~m}$ and $2.80 \mathrm{~m}$ on the girder $\mathrm{E}$, and on the girder $\mathrm{F}$ according to figure 3 .

The plate girders' flanges have a fixed width and variable thickness over the length of the viaduct (Fig. $3 b$ and $3 c$ ). The individual sections of the flanges are connected with a butt weld, and the number of these joints, depending on the girder's construction, ranges from 2 to 5 in the flange. All flange joints, with the exception of $10 \mathrm{~mm}$ outer cap joints in girders A and B (8 joints in total), are covered with onesided diamond pads of dimensions given in figure 3. 


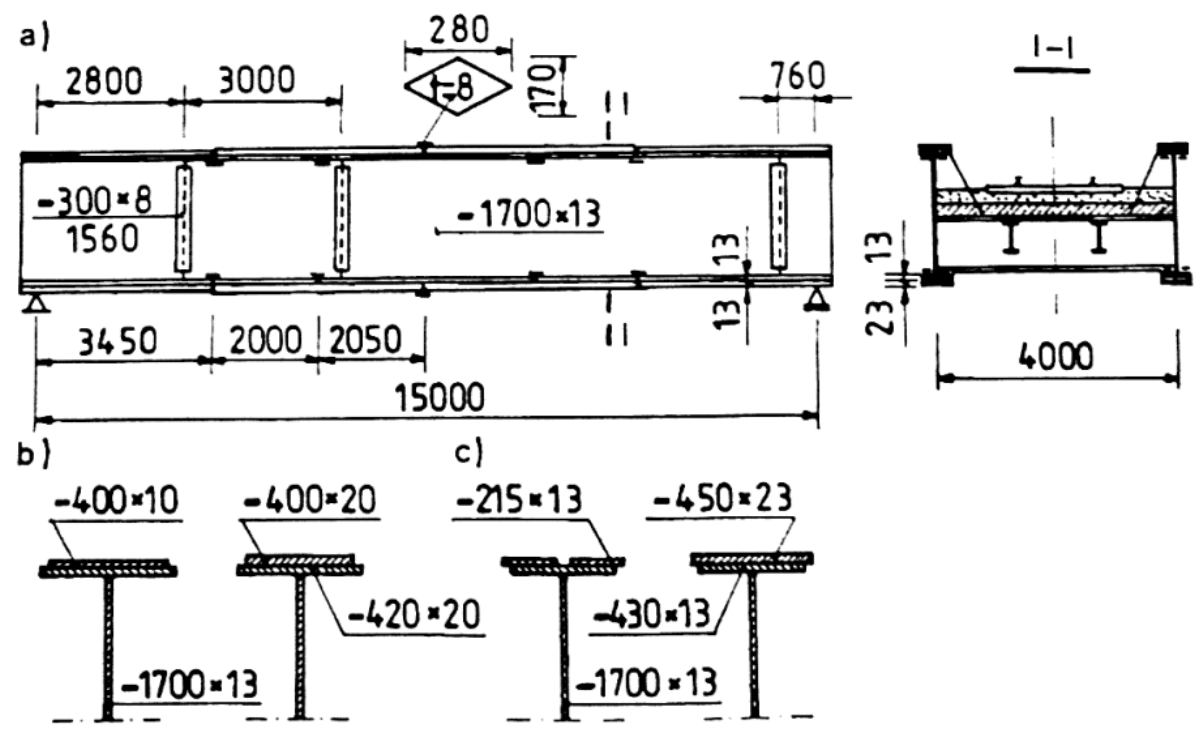

Fig. 3. a) Girder $F$ in the track No. 1, b) cross-sections of girder plates: $A, B, C, D$ and c) of girders $E$ and $F$

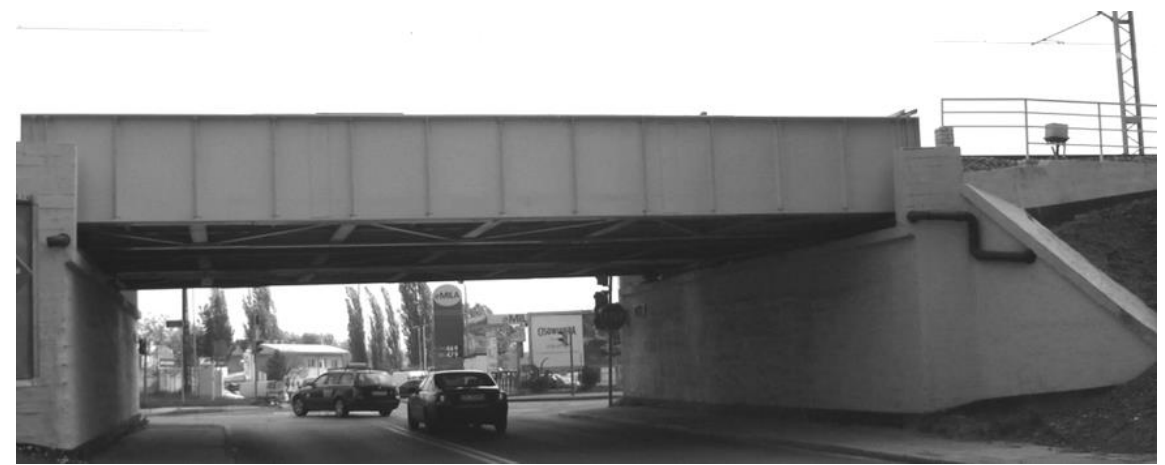

Fig. 4. General view of the railway viaduct

The construction of the viaduct has been subjected to X-ray examinations twice, after 9 and 36 years of operation. The research involved the butt welds of 13 vertical joints of webs and 34 horizontal joints in flanges (18 in upper and 16 in lower flanges). In total, 132 roentgenograms of welds were performed. The numerical list of the tested joints and their determined quality levels in a particular viaduct are shown in table I.

Table I. A numerical list of welds according to the quality level (in the nominative number of radiographs with cracks)

\begin{tabular}{cccccccc}
\hline Girder & \multicolumn{2}{c}{ Joints } & Rtg. & \multicolumn{4}{c}{ Quality level of welds } \\
and track & Type & Number & B & C & D & $>$ D \\
$\mathbf{1}$ & $\mathbf{2}$ & $\mathbf{3}$ & $\mathbf{4}$ & $\mathbf{5}$ & $\mathbf{6}$ & $\mathbf{7}$ & $\mathbf{8}$ \\
\hline \multirow{2}{*}{ A i B } & upper flange & 6 & 12 & - & 4 & 1 & $7 / 3$ \\
track 3 & web & 4 & 20 & - & 1 & 3 & $16 / 12$ \\
& bottom flange & 6 & 10 & - & 3 & 1 & $6 / 2$ \\
C i D & upper flange & 4 & 7 & - & 1 & - & $6 / 3$ \\
track 2 & web & 4 & 20 & - & 1 & - & $19 / 19$ \\
& bottom flange & 4 & 8 & - & - & - & $8 / 6$ \\
E i F & upper flange & 10 & 16 & 1 & 5 & 4 & $6 / 5$ \\
track 1 & web & 5 & 25 & 1 & - & 2 & $22 / 21$ \\
& bottom flange & 10 & 14 & - & 1 & 3 & $10 / 4$ \\
In total & upper flange & 20 & 35 & 1 & 10 & 5 & $19 / 11$ \\
& web & 13 & 65 & 1 & 2 & 5 & $57 / 52$ \\
\hline & bottom flange & 20 & 20 & - & 4 & 4 & $24 / 12$ \\
\hline
\end{tabular}


The roentgenograms of welds, in accordance with the provisions of PN-X/M-69772, were qualified to the appropriate defect class R1 $\div$ R5. Currently, these classes are comparable with the quality levels of welds: $\mathrm{B}+, \mathrm{B}, \mathrm{C}, \mathrm{D}$ and $>\mathrm{D}$, determined according to PN-EN ISO 5917: 2014 and according to these quality levels welds in table I are described. Qualification of up to 114 tested weld sections $(86.4 \%)$ to the level of quality $\mathrm{D}$ and $>\mathrm{D}$ indicates a very low quality of butt welds in the viaduct. These joints are unacceptable in new bridge constructions. 75 roentgenograms (56.8\%) showed 61 cracks, whose length was 10 to $410 \mathrm{~mm}$ in the webs and from 40 to $420 \mathrm{~mm}$ in the flanges. The found cracks in primary research, in 1957, were the reason for riveting the flange joints. In total, 14 joints were riveted; 6 joints in the upper and 8 in the bottom flanges.

Spectrometric chemical analysis of the steel sheet of the upper girder's overlay $E(t=13 \mathrm{~mm})$ showed the composition given in the table II. At the same time, for chemical purposes, the chemical composition of St4S and St4V steel according to PN-88/H-84020 was also given there. The analysis of the chemical composition of steel shows that a significant phosphorus content of $0.107 \%$ has a decisive impact on the properties of the steel tested. Phosphorus above $0.05 \%$ causes coarse graining of the steel and much greater brittleness. It also increases $R_{m}, R_{e H}$ and $\mathrm{HB}$, and reduces elongation and impact strength. Due to the tendency to segregate, it may cause hot or cold cracks. The hot fracture resistance index calculated has an HCS value of 11.62 and exceeds the limit value of 4.0 for low carbon steel [12]. In contrast, the carbon equivalent due to cold cracking $C_{e}^{\prime}=0.318$ and the hardness of the heat affected zone equals $H V_{\max }=182$. These values are lower than the limit values $C_{e} e^{\prime}=0.4$ and $H V=300$.

Table II. Chemical composition of bridge steel and compared steel

\begin{tabular}{cccccccccc}
\hline \multirow{2}{*}{ Type of steel } & $\mathbf{9}$ & $\mathbf{M n}$ & $\mathbf{S i}$ & $\mathbf{P}$ & $\mathbf{S}$ & $\mathbf{C u}$ & $\mathbf{C r}$ & $\mathbf{N i}$ \\
\hline Girder E & 0.12 & 0.535 & 0.02 & 0.107 & 0.054 & 0.032 & 0.064 & 0.042 \\
St4S & $\max 0.24$ & $\max 1.10$ & $\max 0.15$ & $\max 0.05$ & $\max 0.05$ & $\max 0.30$ & $\max 0.30$ & $\max 0.30$ \\
St4V & $\max 0.18$ & $\max 1.30$ & $\max 0.15$ & $\max 0.04$ & $\max 0.04$ & $\max 0.30$ & $\max 0.30$ & $\max 0.30$ \\
\hline
\end{tabular}

Using a sample for chemical tests and a sample from the lower girder's flange overlay $E(t=13 \mathrm{~mm})$, steel hardness measurement was carried out using the Brinell's method, from which the values of $R_{m}=528$ and $422 \mathrm{MPa}$ and $R_{e}=\alpha R_{m}=0.65 .528 \approx 340$ were determined and $275 \mathrm{MPa}$. The values of these limits are in the values provided for by the metallurgical standard for steel St4S and St4V with the size $R_{m}=420 \div 550 \mathrm{MPa}$ and $R_{e m i n}=275 \mathrm{MPa}$.

Steel impact tests carried out on Charpy's specimens made of E-girder's flange steel showed its high aging. The following values of impact energy were obtained: $\mathrm{KV}=6.5,22.7$ and $57.0 \mathrm{~J}$ at temperature: $-20^{\circ} \mathrm{C} ; 0{ }^{\circ} \mathrm{C} \mathrm{i}+20^{\circ} \mathrm{C}$.

\section{Stress analysis in welds and fatigue life of a flange crack}

The purpose of the global assessment of the behavior of the bridge structure was the strength analysis of the maximum loaded butt joints of the individual girder (Table III). The stresses were determined from the constant load and from the basic standard load system at the class $k=+2$ and the operational load with two ET21 electric locomotives (Col. $3 \div 5$ ). The dynamic coefficient $\varphi=1.212$ is taken into account. Column 6 shows the load asymmetry coefficient $\rho=\sigma_{e} / \sigma_{n}$, and column 7 shows the number of load cycles after 70 years of operation (24 and 17 trains per day).

Table III. Maximum stress values in butt joints and coefficients $\rho$ and $N_{i}$

\begin{tabular}{|c|c|c|c|c|c|c|}
\hline \multirow{3}{*}{ Girder } & \multicolumn{5}{|c|}{ Max. stress in $\mathrm{MPa}$} & \multirow{3}{*}{$\begin{array}{l}\text { Load cycles } \\
\quad N_{i} \cdot 10^{6}\end{array}$} \\
\hline & Type of joint & \multirow{2}{*}{ Fixed load } & \multicolumn{2}{|c|}{ Load system } & \multirow[t]{2}{*}{$\rho=\sigma_{\mathrm{e}} / \sigma_{\mathrm{n}}$} & \\
\hline & & & $\mathbf{P}-$ norm. & P - exploit. & & \\
\hline 1 & 2 & 3 & 4 & 5 & 6 & 7 \\
\hline \multirow{2}{*}{ A, B } & web & 20.5 & 102.9 & 45.4 & 0.441 & \multirow{2}{*}{0.613} \\
\hline & bottom flange & 26.3 & 141.1 & 59.1 & 0.419 & \\
\hline \multirow{2}{*}{ C, D } & web & 20.7 & 103.1 & 45.4 & 0.440 & \multirow{2}{*}{0.434} \\
\hline & bottom flange & 22.9 & 121.6 & 51.4 & 0.423 & \\
\hline \multirow{2}{*}{$\mathrm{E}, \mathrm{F}$} & web & 23.7 & 117.3 & 50.9 & 0.434 & \multirow{2}{*}{0.613} \\
\hline & bottom flange & 28.7 & 144.7 & 64.5 & 0.446 & \\
\hline
\end{tabular}


The most dangerous one was the crack in the butt joint with a cross-section of $430 \times 13 \mathrm{~mm}$ in the bottom flange of the girder F. Vertical crack in the root zone of the weld has a height of $2 \mathrm{a}=4 \mathrm{~mm}$ over the entire width of the cover: $2 \mathrm{~b}=21=430 \mathrm{~mm}$. The coordinates of the cracking center $\mathrm{y}=856.5 \mathrm{~mm}$, and the stresses are: $\sigma_{n}=140 \mathrm{MPa},\left(\sigma_{e}=62.4 \mathrm{MPa}\right)$ and $\sigma_{c w}=27.7 \mathrm{MPa}$. The calculations were made according to [8] for the standard and operating load, the results of which are given in brackets.

Critical crack depths were calculated using the formula:

with values:

$$
a_{k r}=\frac{K_{I_{C}}^{2}}{\alpha \pi \sigma^{2} / Q}=8,7 \cdot 10^{-3} ; \quad\left(48,0 \cdot 10^{-3}\right) \mathrm{m}>0,5 t-a=4,5 \cdot 10^{-3}
$$

$\alpha=1.0-$ for internal crack,

$Q=0.86 ;(0.94)$ - according to Fig. 2.10. [8],

$K_{I c}=25 \mathrm{MPa} \cdot \mathrm{m}^{1 / 2}-$ for steel grade St3

Identical values were obtained from the G.R. Irwin formula:

$$
K_{I_{C}}^{2}=\frac{\alpha \pi \alpha_{k r} \sigma^{2}}{Q}
$$

Critical cracking depths are greater than half the thickness of the $0.5 t$ cover plate $=6.5 \mathrm{~mm}$, so the formula for the number of cycles to destroy the element (3) should be from $a_{0}=2 \mathrm{~mm}$ to $a_{k}=6.5 \mathrm{~mm}$ :

$$
N_{c r}=\frac{2 Q^{m / 2}}{(m-2) C \Delta \sigma^{m} M_{k}^{m} \pi^{m / 2}}\left(\frac{1}{a_{0}^{(m-2) / 2}}-\frac{1}{a_{k}^{(m-2) / 2}}\right)
$$

where:

the $\mathrm{C}$ and $\mathrm{m}$ constants are determined by $\mathrm{H}$. Takashima's formulas:

$\log C=0.00483 R_{e}-12.432=-11.104 \rightarrow C=7.875 \cdot 10^{-12}$

$m=4.52-0.0026 R_{e}=3.80$ dla $R_{e}=275 \mathrm{MPa}$

correction coef. $M_{k}=1-0,1(l / b)+(l / b)^{2}=1.9$

$\Delta \sigma=112.3 \mathrm{MPa},(34.7 \mathrm{MPa})$

After inserting (4) to (3) and performing arithmetic operations, we obtained:

$$
N_{c r}=4194 ;(430736)
$$

The number of load cycles obtained should be converted into spectra of real loads. It was assumed that it is analogous to the British railways shown in figure 6 according to [13,14]. By treating $N_{c r}$ as the number of cycles of maximum loads that cause the same fatigue failure as the number of stepwise-variable real loads cycles, the maximum number of $\mathrm{N}_{\max }$ cycles was calculated from the Swanson's formula [14]:

$$
N_{c r} / N_{\max }=\sum_{i=1}^{4}\left(\frac{N_{i}}{N_{\max }}\right)\left(\frac{\sigma_{i}}{\sigma_{\max }}\right)^{2}=0,1976 ;(0.1976)
$$

Finally, the number of load cycles was obtained for individual loads:

$$
\mathrm{N}_{\mathrm{n}-\max }=4194 / 0.1976=21225 ;\left(\mathrm{Ne}_{\mathrm{max}}=430736 / 0.1976=2179838\right) \text {. }
$$

With the assumed operational loads in the form of two ET21 electric locomotives and a permanent load, the cracks in the analyzed butt joint will not develop into fatigue cracks throughout the lifetime of the facility.

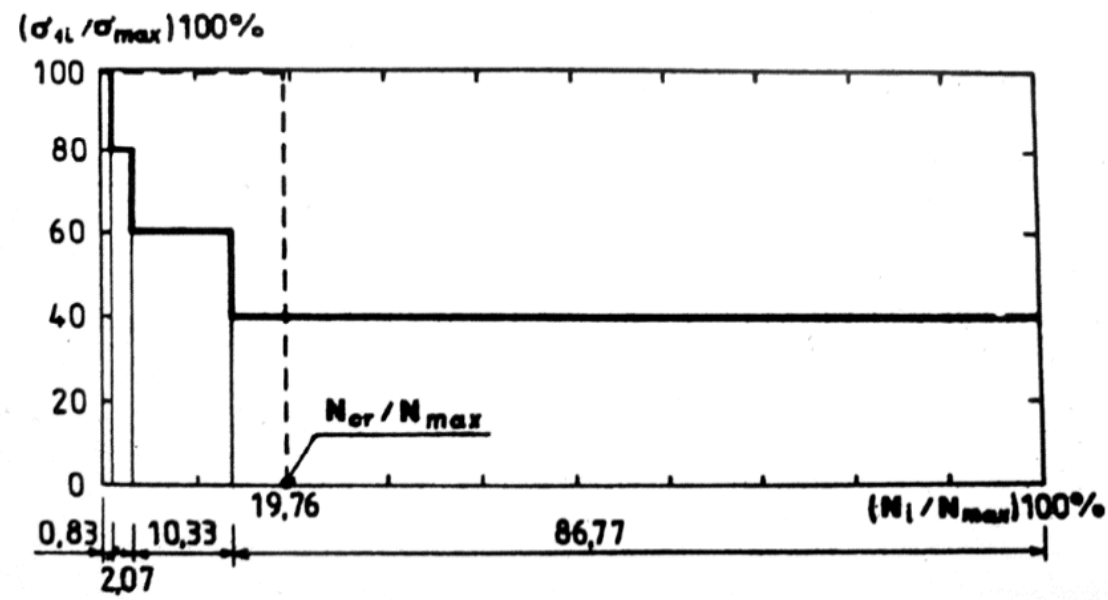

Fig. 5. Stress spectrum for the girder of viaduct [13] 


\section{Summary}

- The results of X-ray examinations of butt welds in the viaduct confirmed that their quality is very low.

- The analysis of Figure 2 shows that the alignment of $Z_{r j}$ with a stress of $\sigma_{e}=103.3 \mathrm{MPa}$ will occur after 89.4 years of operation of the viaduct; in the case of constancy of the daily travel of 24 trains (without taking into account the load spectrum).

- The calculations confirmed the validity of assumptions of the new method for assessing the durability of bridges, the "redundancy" method, regarding accepting actual loads from vehicles on a given used facility.

- Based only on calculations from standard loads, riveting the flange joints with cracks in 1958 seems right.

- In the presented fatigue calculations of the fracture, the influence of the rhombic overlay on the joint and stress concentration were completely omitted [9].

\section{Resources}

[1] Klimpel A., Testing and quality assurance in welding. Part 1, Wydawnictwo Politechniki Śląskiej, Gliwice 1998.

[2] Rykaluk K., Wichtowski B., Strength of a bridge structure with cracks in butt welds. Proceeding of XLIII Scientific Conference KILiW PAN i KNPZITB, t. 5, Krynica-Poznań 1997.

[3] Wichtowski B., Fatigue strength of welded butt joints in steel railway bridges. Scientific Thesis of West Pomeranian University of Technology, no. 572, Szczecin, 2002.

[4] Wichtowski B., Welded butt joints in railway Bridges according to fitness for purpose. Welding Technology Review, 2016, vol. 88(5), 34-38. [CrossRef]

[5] Wichtowski B., Pysiak K., Quality of welded butt joints in Szczecin railway bridges. Biuletyn Instytutu Spawalnictwa w Gliwicach, 2018, vol. 62(4), 59-67.

[6] Fabiszewski A., Previous X-ray examinations of bridge constructions, Scientific Thesis of West Pomeranian University of Technology, nr 6/1958.

[7] Fabiszewski A., Causes of welds breaks of a railway bridge. Welding Technology Review, 1958, (7).

[8] Kocańda S., Szala J., Basics of fatigue calculations, PWN, Warsaw, 1997.

Wichtowski B., Wichtowski M., Fatigue strength of butt welds with overlays according to Eurocode 3. Welding Technology Review, 2011, vol. 83 (3), 36-43.

Wichtowski B., The railway viaduct with the fractures of the butt welds in the light of research, problems of design, construction and maintenance of small bridges. IV National Conference N-T. DWE, Wrocław, Poland 1999.

[9] Wisniewski D., Casas J.R., Ghostn M., Codes for Safety Assessment of Existing Bridges - Current State and Further Development, Structural Engineering International, 2012, 4. [CrossRef]

[10] Blicharski M., Materials Engineering, Steel. WNT, Warsaw, Poland, 2004.

[11] Gurney H., Fatigue of Welded Structures, WNT, Warsaw, Poland 1973.

[12] Czudek H., Pietraszek T., Durability of steel bridge constructions under variable loads. WKŁ, Warsaw, Poland 1980.

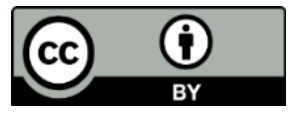

(C) 2019 by the authors. Submitted for possible open access publication under the terms and conditions of the Creative Commons Attribution (CC BY) license (http://creativecommons.org/licenses/by/4.0/). 